\title{
EMILIO PRADOS \\ Y LA GUERRA GIVIL ESPAÑOLA: DOS PROSAS OLVIDADAS
}

En el presente ensayo quisiera referirme a un aspecto de la carrera de Emilio Prados que hasta la fecha ha pasado desapercibido para los críticos que se han ocupado de su vida y obra: su colaboración, durante los primeros meses de 1937, en la revista Ayuda. Semanario de solidaridad. La revista era portavoz de la sección española del Socorro Rojo Internacional (SRI), uno de los muchos organismos creados en Europa, en la década de los 30, con el fin de combatir la amenaza del fascismo. Era una organización, por lo mismo, abiertamente identificada con las causas defendidas por los partidos de izquierda; aunque, como su nombre lo indica, su propósito inmediato no era político, sino más bien humanitario: atender a las víctimas (o a los familiares de las víctimas) de la represión y de la injusticia. Protagonista, en la España de la preguerra, de distintas campañas en defensa de presos políticos, una vez estallada la guerra, el SRI desarrolló una actividad intensa a favor de la causa del Frente Popular, prestando asistencia médica a los heridos, a la vez que atendiendo a las necesidades de la población civil.

La revista $A y u d a$ (una de varias que editó el SRI) empezó a publicarse en Madrid, en febrero de 1936 (durante 1938 se trasladaría a Valencia, para finalmente volver a editarse en la capital española). En un principio, fue dirigida por María Teresa León, pero, ya iniciada la guerra, la dirección pasó a manos de un compañero suyo del Partido Comunista, Isidoro Acevedo. La vinculación política de los directores refleja el grado de organización con que entonces contaba ese partido. Sin embargo, no por ello habría que ver en la revista una sumisión a las ideas de esta agrupación. La revista, como el SRI mismo, asumía una postura "unitaria", como ha escrito Serge Salaün, y reflejaba casi todas 
las facetas del campo republicano ${ }^{1}$. A partir de julio de 1936, la mayor parte de sus páginas estaba dedicada a los problemas muy específicos que enfrentaban los republicanos, tanto en los frentes de batalla como en las ciudades y pueblos de la retaguardia. Se buscaba reforzar la moral de la gente, dando información y consejos. Y también hubo campañas para recaudar fondos con que financiar los distintos servicios, de atención médica y social, que la organización prestaba.

Como en el caso de muchas de las revistas editadas en el campo republicano, el espacio dedicado a la cultura -y más específicamente a la literatura - era considerable. Este rasgo, desde luego, estaba en consonancia con la política oficial del gobierno, que identificaba la lucha antifascista con una defensa de la cultura misma del país. Por otra parte, la literatura -y sobre todo la poesía - constituía una forma muy eficaz de recaudal dinero, si no a través de la revista misma, sí a través de los libros que el SRI también publicaba (el SRI, nos informa Salaün, "eré una de las organizaciones que más libros y antologías poéticas había editado"'2). Existió, por esto mismo, una estrecha rela. ción entre los escritores y el SRI, hecho que, como digo, quedí reflejado en las páginas de Ayuda. De hecho, colaboró en ella un gran número de los escritores más relevantes de la Espã̃ leal: Antonio Machado, León Felipe, Rafael Alberti, María Te resa León, Ramón J. Sender, César M. Arconada, Miguel Her nández, Pedro Garfias, Antonio Aparicio, Manuel Altolaguirr y Emilio Prados (entre otros). Nómina de por sí bastante signifi cativa, pero que se enriquece todavía más si se incluye tambiér a los colaboradores (y simpatizantes) americanos, muchos di ellos figuras de primera línea, como, por ejemplo, los cubano Nicolás Guillén y Pablo de la Torriente Brau, el argentino Raú Gronzález Tuñón, el chileno Vicente Huidobro o el norteameri cano Langston Hughes (en traducción del cubano Lino Nova Calvo).

Emilio Prados parece haber empezado a trabajar para el So corro Rojo Internacional poco después de llegar a Madrid, e] septiembre de 1936 (el inicio de la guerra lo había sorprendid en su Málaga natal). Fueron días de una actividad muy intensa

${ }^{1}$ Serge Salaün, La poesía de la guerra de España, Castalia; Madrid, 198: p. 343. Sobre Ayuda, véase también Rafael Osuna, Las revistas españolas ent dos dictaduras: 1931-1939, Pre-textos, Valencia, 1986, pp. 145-146.

2 Salaün, loe. cit. 
en que el poeta fue asumiendo a la vez tareas y responsabilidades muy diferentes, tal y como él mismo recordaría años más tarde, en una carta escrita ya al final de su vida:

En Madrid estuve en el frente con las Brigadas Internacionales, al mando del General Kleber, en el Pardo. Trabajé en la Alianza de I[ntelectuales] A[ntifascistas] y en "Cultura popular" con el "Socorro Rojo" en "La alameda de Osuna" y más tarde cuando las cosas se empeoraron [alusión, sin duda, al 7 de noviembre, fecha en que se inicia el sitio de Madrid] con la Junta de Defensa, ocupándome de un servicio particular de radio, con Arturo Serrano Plaja, y más tarde con Luis Cernuda. En "Madrid en armas". Allí trabajé para Europa y América. [El poema] "Ciudad sitiada" lo leí entonces. Otra infinidad de cosas me ocupaban. "Altavoz del frente" y "El quinto regimiento" (causa de las canciones que con Alberti y $\mathrm{Ma}$ [ría] T[eres]a [León] compuse entonces y que andan por ahí. ¡En fin, lo que se pudo! ${ }^{3}$.

Breves referencias publicadas tanto en El mono azul, la revista de la Alianza de Artistas e Intelectuales Antifascistas, como en Milicia popular, el diario del $5^{\circ}$ Regimiento, echan cierta luz sobre algunas de estas actividades. El 19 de noviembre, por ejemplo, en El mono azul, se nos informa: "La Alianza sigue su labor de propaganda. En este momento al servicio de la Junta de Defensa de Madrid y desde la emisión «Madrid en armas», nuestros compañeros Arturo Serrano Plaja y Emilio Prados han organizado una serie de programas de agitación y propaganda en acción conjunta con el Altavoz del Frente" "4. Por otra parte, unos días después, en las páginas de Milicia popular, leemos que Prados ha estado presente en una cena que organizó el $5^{\circ}$ Regimiento para despedir a un grupo de personalidades artísticas y culturales que iban a ser evacuados: "Al acto asistieron, además [de los evacua-

${ }^{3}$ Fragmento de una carta a José Sanchis-Banús, fechada 15-X-59. Reproducido por Patricio Hernández, Emilio Prados: memoria del olvido, Universidad de Zaragoza, Zaragoza, 1986, t. 2, p. 442. Según Mercedes Díaz Roig, Prados también participó, por aquel entonces, en el salvamiento de las obras del Museo del Prado. Cf. Díaz RoIg, Poesía comprometida de Emilio Prados publicada durante la guerra civil española, tesis de licenciatura, UNAM, México, 1970 , p. 15.

"Anónimo, "Notas", El mono azul (Madrid), núm. 13 (19-XI-36), s.p. Véase, al respecto, Carmielo Garitaonaindia, La radio en España 1923-1939. (De altavoz musical a arma de propaganda), Universidad del País Vasco/Siglo XXI, Madrid, s.f., p. 221. 
dos], los comandantes del $5^{\circ}$ Regimiento, Carlos y Líster; lo poetas Alberti, León Felipe, Emilio Prados y Aparicio; y la escri tora María Teresa León"5. Mientras que el 12 de diciembre, nuevamente en Milicia popular, se anuncia que: "El folleto de la «Ediciones del $5^{\circ}$ Regimiento» sobre la historia del Batallón Thae] mann será hecho por nuestros queridos camaradas María Teres León, Alberti y Prados". Y luego se agrega: "Nuestros amigc han sido enviados a Albacete por la comisión de Trabajo Socić del $5^{\circ}$ Regimiento para recoger materiales y hablar con los orge nizadores del glorioso Batallón'"6.

Todas estas actividades datan de noviembre y diciembre $\mathrm{d}$ 1936. ¿Qué fue de las otras ocupaciones anteriores que Pradc menciona en su carta? Al hablar concretamente del SRI, el poet especifica haber trabajado en "Cultura popular", en "La ali meda de Osuna" (un barrio en las afueras de la ciudad). ¿Se tr. taba simplemente de una oficina de divulgación cultural? ¿ $\mathrm{O}$ ti vo algún fin educativo más específico? No he podido averigu: nada al respecto. Lo que sí sabemos, gracias a la investigació pionera de Carlos Blanco Aguinaga7, es que por estas fech Prados "dirigió una guardería de niños", trabajo que bien pr dría haber correspondido (al menos, en parte) a este compromis con el SRI que él señala en su carta. El tema no carece de interé como veremos más adelante.

Sea cual sea el trabajo que Prados haya desempeñado pa el SRI, el hecho - que no deja de ser paradójico- es que no en

${ }^{5}$ Cf. Anónimo, "El antifascismo y la cultura. Hombres de ciencia en $5^{\circ}$ Regimiento. Emocionante despedida", Milicia popular (Madrid), Año núm. 117 (2-XII-36), p. 2. Un día después, en la misma revista, se anunc que: "A las siete y media hablará desde nuestra emisora el poeta Emilio Pr dos, de la Alianza de Intelectuales Antifascistas". Anónimo, "Emisora del Regimiento de Milicias Populares', Milicia popular (Madrid) Año I, núm. 1 (3-XII-36), p. 4.

6 Anónimo, "La historia del batallón Thaelmann será hecha por Ma Teresa León, Rafael Alberti y Emilio Prados', Milicia popular (Madrid), A I, núm. 127 (12-XII-36), p. 3. Aunque, hasta el 26 de diciembre, se sigr anunciando como de próxima aparición, parece que el folleto nunca llegć editarse. El romance que escribió Prados en homenaje "Al batallón Tha mann", tal vez haya correspondido a este proyecto. Cf. Prados, Poesías co pletas, edición de Carlos Blanco Aguinaga y Antonio Carreira, Aguilar, Mé co, 1975 , t. 2, pp. 583-586. En adelante toda referencia a la poesía de Prac se basará en esta edición y se identificará mediante el número del tomo, seg do por el número de la página.

7 Carlos Blanco Aguinaga, "Emilio Prados. Vida y obra", $R H$. 1960, núms. 3/4, p. 17. 
pezó a colaborar en Ayuda, la portavoz madrileña de la organización, hasta después de haberse trasladado de Madrid a Valencia. Este traslado, que parece haber ocurrido a finales de diciembre de 1936, se debió a la invitación que el poeta recibió de dirigir una nueva colección de libros que iba a editar en Valencia el Ministerio de Instrucción Pública: las "Ediciones Españolas". Por desgracia, la invitación no se mantuvo en pie, de modo que, al llegar a Valencia, Prados se encontró de repente sin trabajo. Siguieron meses difíciles, durante los cuales sólo logró salir adelante gracias a la generosidad de sus amigos: entre otros, del general Kleber, que lo hospedó en su casa en las afueras de Valencia, así como de Manuel Altolaguirre, que lo ayudó económicamente, al lograr que se publicara un libro suyo, una importante colección de su poesía más reciente, su Llanto en la sangre. Romances. 19331936. Tiempos difíciles, sí. Pero, a pesar de estos problemas personales, y a pesar del panorama cada vez más angustiante que presentaba la guerra misma (en enero de 1937, por ejemplo, Málaga, su ciudad natal, cayó en manos de Franco), la dedicación del poeta a la causa republicana seguía tan firme como siempre.

Las colaboraciones de Prados en Ayuda fueron apareciendo durante estos primeros meses de su estancia en Valencia; es decir, entre enero y mayo de 1937. Fueron cinco en total: dos en prosa y tres en verso. Los poemas, aunque ofrecen variantes de cierto interés, ya han sido recogidos en las Poesías completas ${ }^{3}$. Las dos prosas, en cambio, representan una auténtica novedad den-

${ }^{8}$ Los textos son los siguientes: "Soledad de Málaga (Fragmento de romance escenificado)", núm. 48 (27-111-37), p. 1; "Nueva fe (Sobre la guerra)", núm. 51 (18-IV-37), p. 1; y "Nueva fe (Triunfo sobre la muerte)", núm. 57 (30-V-37), p. 1. El primero corresponde a "Soledad de Málaga" (1, pp. 608-611); el segundo, a "Meditación en la noche" (1, pp. 652655); y el tercero, a dos poemas: "Nueva fe (Sobre la muerte)" (1, p. 699) y "Cinta del tiempo" (1, pp. 694-695). Mi agradecimiento al personal del Archivo Histórico de la Guerra Civil, de Salamanca, por la ayuda prestada en la consulta de esta revista, hoy una verdadera rareza bibliográfica. Las variantes de mayor interés atañen a los títulos. Si bien los dos últimos textos parecerían indicar que el poeta pensaba poner el título de Nueva fe a la nueva colección que entonces escribía, el primero, identificado como "Fragmento de un romance escenificado", tendería a confirmar la afirmación de Altolaguirre de que su amigo se interesaba entonces por el teatro. Véase Altolaguirre, "Nuestro teatro", Hora de España (Valencia), núm. 9 (septiembre 1937), pp. 29-37. Lo curioso es que la caída de Málaga también le inspiró a Altolaguirre una especie de "romance escenificado", Las barcas, 215, del cual igualmente se conserva sólo un fragmento. Véase Altolaguirre, "Romance de la pérdida de Málaga", Mediodía (La Habana), núm. 40 (1-XI-37), p. 13. 
tro de la obra de Prados. De hecho, hasta la fecha, entre la obr: publicada en vida del poeta, la única otra muestra de su pros: que se conoce es su reseña de Viento del pueblo, de Miguel Hernán dez, un libro editado, por cierto, por el SRI ${ }^{9}$. En vista de ello y en vista del interés que encierran para el estudio de la vida obra de Prados, a continuación centraré mi atención en estos do textos. El primero se dio a conocer en el número 36 de la revist (2-I-37). Titulado "Los niños tiznados de España", reza com sigue:

Los he visto pasar, durante mucho tiempo, al lado mío. He vivid muchos años junto a ellos, esos niños tiznados que van descalzc y sucios, errantes y medio desnudos por los muelles, pordiosandc con su lata vacía, las sobras de la escasa comida de los marinero: Son niños huraños, desconfiados, cuya mirada es difícil encontré bajo las manchas oscuras del carbón, y aún más difícil bajo lí manchas ariscas que el mal trato diario, el desprecio, el abanóon la miseria y el hambre han ido dejando constantemente en la ten blorosa soledad de su infancia. Se les ve cruzar como sombras mi dosas, chorreantes de hollín y de lluvia, y acercarse sin pregunt: a los costados de los grandes buques para mirar por las rendijas c las claravoyas el misterio luminoso de la vida que encierran ba los hierros curvos de su casco. Se les ve, durante las madrugadi de frío, apelotonarse temblorosos unos contra otros, buscanc abrigo para descansar, bajo las grandes cajas de mercancías q1 aguardan en los muelles.

Yo he visto jugar a estos niños. Sí, los he visto nadar desnud bajo el agua sucia, grasienta, del puerto, y subir luego medio as xiados, sonrientes, llevando entre las manos algunos trozos de ca bón que les iban a producir unos céntimos para aquel día. Ést son los únicos juegos de los niños tiznados.

También he visto pasar a mi lado, he vivido mucho tambi con los niños areneros, hijos de pescadores; niños sonrientes, a la sonrisa precoz de la tristeza; niños con miradas de cobre, en 1 que saben ya alternar, con la dureza del reproche justo, la dulzu paternal del reconocimiento.

Estos niños sin escuela apenas tienen día suficiente para tern nar su trabajo; trabajo que a veces realizan dentro de las mism cuevas que les sirven de viviendas. Cargan con la arena los sac pesados que desfiguran sus espaldas, y allí van ofreciendo su pok mercancía, que casi siempre es rechazada o recibida entre desp

${ }^{9}$ Prados, "Miguel Hernández: Viento del pueblo", Nuestra Bandera (B celona), núms. $1 / 2$ (enero-febrero 1938). 
cio y malas palabras. Recuerdo, entre los niños areneros de Málaga, de Miraflores del Palo, el número de los pequeños camaradas muertos en los derrumbamientos de las minas, cuando recogían la arena que iba a producirles unos céntimos, y a veces sólo un pedazo duro de pan con que matar el hambre de la jornada.

Estos son los únicos juegos que a estos niños ofrecen los que hoy, del otro lado de nuestra guerra, se alzan contra la España que nacía de paz, de igualdad de derechos y de trabajo.

Ellos, los que han pasado ijunto a estos niños, sin verlos, los que con la organización sangrienta de su sistema social fueron causa del desnivel trágico en que vivieron, no escatiman ahora tampoco ninguno de los medios de destrucción para impedir el avance natural hacia una era en que los niños desconozcan la injusticia actual para la que sufren.

Vosotros, niños areneros, niños tiznados de los muelles, niños abandonados, que sólo habéis conocido como único abrigo el de la humedad salobre de los puentes; hijos de los antiguos obreros parados, que antes paseabais vuestros enormes ojos hambrientos por los escaparates repletos de las ciudades... Vosotros ya conocéis de pleno el escándalo, el dolor, el espanto y el color de vuestra sangre sobre las piedras derramada cobardemente. Alguno de vosotros, ya adolescente, ha sabido escoger su lugar en la lucha.

Aguardad. Nosotros os prometemos, niños españoles, niños tiznados de los muelles, que muy pronto podréis tener juguetes, libros, bibliotecas y aire pleno para jugar, y esta vez lo tendréis sin miedo, porque será vuestra toda la playa, todo el mar, toda la tierra en que juguéis.

¡Madres españolas, hombres libres, luchadores de nuestras filas, contribuid todos para que estos niños puedan jugar entre nosotros este año!

Al leer este texto, seguramente vendrá a la mente de muchos lectores el poema "Alerta" de Prados, texto dedicado "A Manuel Jiménez Ojeda, “El Capitán», niño asperonero de las playas de Málaga que murió sepultado bajo la arena, y a todos los niños de las playas del mundo". En este poema, escrito entre 1930 y 1932, Prados había denunciado, por primera vez, la terrible miseria en que vivían los niños pobres de su ciudad, así como la fría indiferencia, cuando no la crueldad, con que eran tratados por la mayoría de la gente a su alrededor:

Niños que no dormían que nunca conocieron el sabor del descanso que apenas si andaban y ya tenían abiertos los ojos 
para siempre sin párpados colgados sobre el viento, iban saliendo lentos uno a uno de sus lóbregas cuevas.

Sin hablarse se unían y caminaban juntos.

Una misma tristeza cobarde

perseguía sus débiles latidos... (1, p. 443).

Este compromiso de Prados con la suerte de los niños pobre: de Málaga obviamente constituía una experiencia fundamenta en su vida. Y no por nada, años después, ya exiliado en México al escribir a un sobrino que vivía en Málaga, habría de pregunta por "los chiquillos que recogí y eduqué" allí, agregando cor cierta insistencia: "Mándame fotos de gente de las calles, de lo mercados y del Palo. Pregunta en el Palo por «El tío de los pe rros", por el que fue Juanillo y hoy será un tío como tú. Dile d parte mía que me acuerdo mucho de ellos" ${ }^{10}$. De todo est mundo infantil de los bajos fondos de la sociedad malagueña Pra dos nos ha dejado, en "Los niños tiznados de España", un testi monio vívido y detallado como pocos.

Pero, con todo, el interés de este artículo rebasa, desde luegc lo meramente anecdótico. El texto también llama la atención po la claridad con que expone los términos en que se dio el comprc miso político del poeta, tanto antes como durante la guerra. Cc mo se puede observar, lo que reclamaba Prados era un régime "de paz, de igualdad de derechos y de trabajo"; y, para logra este fin, siguiendo a Marx, veía la necesidad de deshacerse de 1 "organización sangrienta" del sistema social español (es decis de su organización capitalista), por ser ésta la causa de las des gualdades e injusticias sufridas. Aunque, dicho esto, se ve qu Prados no parece haber creído que bastara con reorganizar el e. tado según lincamientos marxistas o socialistas; que tambié seguía siendo fundamental para él el comportamiento ético d individuo. De ahí su crítica, presente a lo largo de su artícul a quienes, como en la parábola de Cristo sobre el buen samariti no (Luc., 10, 25-37), "pasan junto a estos niños sin verlos". ] cambio en la organización económica y social puede facilitar li condiciones objetivas necesarias para conseguir el ideal de vic que se busca, parece decirnos Prados, pero, para poder realizar. plenamente, este cambio estructural tiene que acompañarse c un auténtico compromiso del individuo para con su prójimo.

${ }^{10}$ Fragmento de una carta de Prados a Angel Caffarena, fechada el 28 53. Apud Hernández, op. cit., t. 2, p. 393. 
Finalmente, hay que dejar constancia de la calidad, nada rutinaria, del estilo de nuestro autor. Aunque el texto habrá sido escrito con fines exclusivamente políticos, sin pretensión literaria alguna, no cabe duda de que, por la moderación de su tono, así como por la exactitud de su lenguaje, se distingue notoriamente de la mayoría de los artículos escritos durante la guerra con el fin de defender tal o cual causa. Prados sí acude a ciertos recursos rítmicos: la serie de anáforas ("he visto pasar...", "he visto jugar...", "he visto nadar..."), por ejemplo, que estructura la primera parte del texto; o las enumeraciones reiterativas con que, al final del mismo, se interpela a los niños: "Vosotros, niños areneros, niños tiznados de los muelles, niños abandonados..." Pero, con todo, el autor ha preferido no abusar de este tipo de énfasis. Si el texto logra su propósito, es gracias, sobre todo, a la veracidad misma de las observaciones: la "lata vacía" con que los niños van pordiosando; "el agua sucia, grasienta del puerto" en que se sumergen en busca del carbón, o "la humedad salobre de los puentes" que los abrigan en la noche. Observaciones que, a su vez, son fruto de la experiencia directa del autor. Prados no necesita ni exagerar ni enfatizar: los hechos hablan por sí solos.

La segunda prosa salió publicada cuatro meses después de la primera, en el número 55 de la revista (16-V-37). La relación entre las dos es muy estrecha. Si bien en el primer texto el poeta había buscado identificar la causa republicana con la de los niños pobres y desamparados de las clases más bajas de la sociedad, ahora lo que le preocupa es la suerte misma de esos niños durante la guerra. La preocupación era generalizada en el campo republicano e incluso había empezado a encontrar eco en la literatura escrita por los intelectuales y poetas comprometidos con la causa. Vicente Aleixandre, por ejemplo, ya había publicado una "'Oda a los niños de Madrid muertos por la metralla"11.

Desde luego, todos los días y en todos los frentes morían niños inocentes. Pero lo que hizo que Prados se volviera especialmente sensible a esta problemática fue sin duda la masacre, por parte de la fuerza aérea franquista, de centenares de mujeres y niños indefensos que, tras la caída de Málagra, habían salido huyendo por la carretera de Almería en un intento por refugiarse

11 AlemXandre, "Oda a los niños de Madrid muertos por la metralla", Ahora (Madrid), núm. 17 (18-1-37). Excluido de las Obras completas de Aleixandre, el poema fue reproducido por SALAÜN, op. cit., pp. 333-335. 
en la zona republicana. Sobre este acto de barbarie, que produjc una ola de indignación en la prensa republicana, Prados seguramente habría escuchado testimonios personales de primera manc al entrevistarse con aquellos de sus paisanos que escaparon de le masacre y lograron llegar hasta Valencia. De ellos parece habeı eco en su poema "Soledad de Málaga", donde, a través de la voz de una mujer anónima, se pregunta con verdadera angustia po] la suerte de los niños desaparecidos:

Entre las sombras del monte, bajo el crujir de las balas, perdí lo que más quería, perdí lo que más amaba. Hijos, ¿dónde os encontráis?, vuestros pies, ¿por dónde marchan? ¿Os mueve acaso la vida o vuestra sangre cuajada en las piedras del camino aguarda nuestra venganza? (1, p. 610).

El gobierno de la República tenía muy presente el problem y en un esfuerzo por salvar la vida de la población juvenil habí iniciado una campañ் para evacuar a los niños de las zonas d peligro. Prados obviamente veía la conveniencia de esta medid (una medida que, por lo visto, no fue apoyada por todos) y co el propósito de convencer a los padres de familia que se negaba a participar en la campaña, escribió este segundo artículo, qu tituló, de manera provocativa, “¿Qué haces tú de tus hijos?"

Realmente, es incomprensible la obstinada oposición que cada díi con mayor resistencia, encontramos para conseguir la necesar evacuación de los niños y mujeres de nuestra capital. La causa c ello podría parecernos heroica si no entrase de lleno dentro de li límites de lo patológico. Porque lo heroico tiende a la sublimacić del valor individual o colectivo, pero siempre partiendo de un est do de conciencia, de una voluntad de superarse en un momen determinado de la vida; pero a la cual no podemos arrastrar, c su falta de conocimiento, a los seres que nos rodean, cuando inv luntariamente y con torpeza en ello buscamos mayor realce a nuє tros actos o también más tranquilidad para lograr su completa re lización. Así, hoy, en Madrid, ejemplo universal de heroísmo fortaleza, nos encontramos con el caso de que estos mismos hor bres que labran con su sangre y con su dolor tal vez la página $\mathrm{m}$ 
sublime de toda nuestra historia, empequeñecen de cierta forma su brillante gesto al no querer separarse de sus hijos ni de sus mujeres, obligando a éstos a soportar a su lado toda una serie de peligros y penalidades innecesarios, de lo cual muchos se arrepienten, por desgracia, demasiado tarde para poner remedio a ello. Heroísmo, sí, pero también inteligencia. Recapacite cada compañero en los motivos por los cuales lucha, y piense luego también en los motivos que le mueven a la negación de que os hablo. Cada padre de familia, aun en los momentos de mayor dureza en la lucha, lleva clavada en su memoria la estampa tierna y dolorosa de sus hijos amenazados.

Cada padre también siente iluminársele ardorosamente dentro de sus venas toda su sangre al pensar que la victoria conseguida alejará para siempre de sus hijos esta amenaza de hoy de la guerra, y las aún más temibles, las amenazas dolorosas que hicieron enturbiar con su memoria las horas de alegría de su nacimiento: las de la esclavitud, la humillación, el hambre, que ya miraban sobre la cuna de su recién nacido. Cada padre tiene también presente en la trinchera la estampa de la paz y fáciles promesas que la aurora cercana ofrece para sus hijos y con mayor ardor se lanza a conseguirla, aunque derrame toda su sangre para alcanzar sus reivindicaciones. Pero que piense cada padre tambiẻn: ¿A quién llevará las alegrías de esta victoria si por su egoísmo puramente sentimental, por no quererse separar por un corto plazo de sus hijos, encuentra, al volver de las trincheras, vacío su hogar, destruido, desmoronado trágicamente entre las llamas oscuras de la guerra? Entonces sentirá inútil todo su esfuerzo ante el desierto sentimental que la realidad le levanta.

Piense y piense bien el que tenga hijos. No podemos obligarles de ninguna manera; no tenemos derecho tampoco para hacerlo, a que permanezcan expnestos a la mnerte más terrible y a los mayores sufrimientos. Será sobre nosotros mismos sobre los que recaiga toda la culpa de estas penas y serán estos niños de hoy los que en un próximo mañana nos pidan cuenta de los que murieron.

Cuando la fatalidad nos conduce sin solución a un triste trance, nos queda sólo la rebeldía del silencio; pero, ¿es que hoy estamos dentro de estas condiciones? De ninguna manera. Nuestra organización internacional tiene ampliamente resuelto este asunto. Aquí, en España, y fuera de ella, en Francia, Bélgica, Holanda, Inglaterra, Rusia y Méjico, funcionan Comités de ayuda, los cuales, de acuerdo con el Gobierno del Frente Popular de nuestra República, acuden a defender a nuestros niños de la manera más solícita y eficaz. Los niños que salen al extranjero (los más felices, por alejarse de nuestra guerra), antes de ser enviados definitivamente a otro país están sometidos a un detenido reconocimiento para que 
el clima en el cual hayan de vivir sea el más conveniente a su cons. titución física. Más tarde, ya en el lugar de su destino, los niños están perfectamente atendidos de todas formas y encaminados pa. ra su educación física y moral más convenientes.

Yo he visto en Madrid, aterrorizado por ello, las caras espanta das de estas criaturas, cuyos ojos abiertos, sin comprender apena: nada de lo que ocurría a su alrededor, se clavaban enloonecidos er el aire. No podré nunca olvidar las miradas fijas, los rostros desga rrados, la prematura ruina de los que conocieron más de cerca e horror de los bombardeos fascistas. Hay que impedir que estos ni ños, más tarde, nos acusen. ¿Cómo? Alejándolos de estos peligros puesto que existen ya magníficos lugares creados especialmente pa ra ello.

Sus mismas caras inocentes pasan hoy, al lado mío, riendo po los pueblos de España, camino de Francia, por los barcos de Méji co. No olvidaré la alegría de la última expedición a dicho país, co mo tampoco olvidaré la protesta de los que, por rebasar la edad re glamentaria (de seis a trece años), tuvieron que quedarse co: nosotros.

Escribo bajo la impresión alegre de su despedida y bajo la an gustia del recibimiento de los recién llegados niños de Málaga, en fermos y entontecidos de dolor después de su evacuación atropella da y tardía.

Cuando pueden tener un presente claro de paz y salud, en lu gar de una muerte posible, el separarnos temporalmente de estc niños no debe ser un sacrificio sino una obligación perentoria; si contar que además, en nuestro caso, es también una disciplina d guerra.

Camarada, atiéndenos. El S[ocorro] R[ojo] I[nternacional] 1 pregunta: ¿Qué haces tú de tus hijos?

Si bien, en un principio, el gobierno del Frente Popular, ayı dado por los comités internacionales de ayuda, buscó reubicar los niños en distintas partes de la zona republicana que estuvi ran lejos de los frentes de batalla (las costas de Valencia y de $\mathrm{C}_{\text {i }}$ taluña fueron considerados los lugares más idóneos), poco a p co, y en parte a instancias de estos mismos comités de ayuda, pensaba más bien, como señala aquí Prados, en la convenienc de enviarlos al extranjero. Con el tiempo el gobierno enviaría varios miles de niños a la Unión Soviética, Francia, Bélgica e I glaterra ${ }^{12}$. Sin embargo, la primera expedición, y tal vez la m:

${ }^{12}$ Curiosamente, entre los que se ocuparían de los niños enviados a I glaterra, figuraría otro poeta de la generación de Prados, Luis Cernuda. ] 
famosa, fue la que llevó un grupo de 450 niños españoles a Morelia, México; grupo que, por ello mismo, llegó a identificarse como el de "Los niños de Morelia". A esta expedición hace alusión Prados al final de su artículo. Y si la tiene muy presente será porque él mismo seguramente acaba de participar en su organización, ayudando a enviar un buen número de niños desde Valencia a Barcelona, ciudad de donde partirían, junto con otros niños recogidos en Cataluña, para México. El 20 de mayo los niños saldrían, en tren, de Barcelona con destino a Burdeos; y en Burdeos tomarían el vapor francés, el Mexique, a La Habana, donde se reunirían brevemente con J. R. Jiménez ${ }^{13}$, y de La Habana, a Veracruz. El 10 de junio, y después de una recepción calurosa y multitudinaria por parte del pueblo mexicano, llegarían a su destino final, Morelia. El artículo de Prados fue escrito, como él mismo señala, "bajo la impresión alegre de [esta] despedida"'14.

Como ya se ha dicho, esta campaña del gobierno para evacuar a los niños no fue acogida con la misma confianza por todos los padres de familia. En su artículo Prados aborda el tema con discreción, pero también con firmeza. Y desde nuestra perspectiva actual, se ve que la historia le ha dado la razón. Si bien la separación, en la mayoría de los casos, resultó ser mucho más larga de lo que se había previsto, no cabe duda de que la medida le salvó la vida a muchos niños; y de que, aun cuando no hubieran muerto durante la guerra, estos mismos niños (sobre todo los de Morelia), de haberse quedado en España, difícilmente hubieran tenido las posibilidades de vida de las que gozarían en sus nuevos países de adopción. La separación significaba un sacrificio muy grande en su vida afectiva, pero a la larga parece que la decisión tomada fue la mejor.

Sea como sea, este artículo, con su referencia a "nuestra organización internacional", parecería indicar que la vinculación de

muerte de uno de los evacuados le inspiraría a Cernuda su hermosa "Elegía a un muchacho vasco muerto en Inglaterra', Véase, al respecto, RAFAEL Martínez Nadal, Españoles en la Gran Bretaña. Luis Cernuda. El hombre y sus temas, Hiperión, Madrid, 1983, pp. 22-30.

13 Véase J. R. Jiménez, "Francisco González Aramburo (Niño español del Mexique)', Guerra en España, Seix Barral, Barcelona, 1985, pp. 168-169.

${ }^{14}$ La historia de la expedición ha sido estudiada a fondo por Dolores Pla Brugat, Los niños de Morelia, INAH, México, 1985; trabajo que ha sido imprescindible en la preparación del presente artículo. Véase también el testimonio personal de Emeterio Payá Valera, Los niños españoles de Morelia (El exilio infantil en México), Edamex, México, 1985. 
Prados con el SRI, iniciada en el verano de 1936, seguía en pie un año después, a pesar del traslado del poeta a Valencia. En el verano de 1937 participaría en el II Congreso de Artistas y Escritores Antifascistas, preparando dos antologías: su Homenaje al poeta Federico García Lorca, contra su muerte y también (en colaboración con Antonio Rodríguez Moñino) su Romancero general de la guerra de España. En noviembre de 1937 volvería a mudarse, esta vez a Barcelona. Allí trabajaría en el Ministerio de Instrucción Pública y también ayudaría a María Zambrano y otros en la dirección de la revista Hora de España. Sin embargo, a pesar de estas y otras actividades, su compromiso con los niños españoles seguiría igualmente firme. Estando en Barcelona, escribiría su poema "Perdida infancia (Elegía a un niño muerto en Barcelona durante los últimos bombardeos fascistas)'" (1, pp. 730-732). Por otra parte, llevado por la misma preocupación, también escribiría su poema "¡Ya llegan los niños, madre! . . (Canción para los niños refugiados en Cataluña, con motivo de la Semana del Niño)", con su angustioso refrán:

\author{
¡Ay, madre, \\ los niños vienen: \\ llegan ya! \\ ¿Quién los cogerá? \\ Bajan de la nieve, \\ madre, \\ llorando suben del mar. \\ ¿Quién los cogerá? (1, pp. 712-715).
}

Y, desde luego, este compromiso no terminaría con la guerra. Y: exiliado en México, y a pesar de haber perdido para entonces to do interés en cuestiones políticas, Prados seguiría asumiendo e mismo tipo de responabilidades. Así, al lado de los trabajos tipo gráficos realizados tanto para la revista Cuadernos Americanos comı para la Editorial Séneca (trabajos con que más o menos se gana ría la vida), Prados también desempeñaría el papel de mentor ‘ "'maestro sin cátedra" en el Instituto Luis Vives, escuela funda da en México por el Gobierno Republicano en el exilio. Asimis mo formaría parte del Patronato Pro Niños Españoles, que entr otras actividades importantes, gestionaría la creación de Casa Hogar para los Niños de Morelia, esos mismos niños que Prado había ayudado a enviar a México, desde Valencia, en mayo d 
193715. Incluso, a dos de estos niños de Morelia, ambos huérfanos, los llevaría a su casa a vivir. Es decir, entre el poeta del exilio y el poeta de la guerra, tal y como se proyecta en este segundo artículo de Prados, hay una clara línea de continuidad. La actividad política desaparece, pero se mantiene incólume el mismo compromiso moral.

Así, resumiendo, podemos decir que las dos prosas de Prados ofrecen datos novedosos a quien se interese en la actuación del poeta durante la Guerra Civil española, pero que el valor fundamental de los textos rebasa los estrechos límites de ese período, dejando ver la línea ininterrumpida que vincula las inquietudes sociales que tuvo el poeta durante su juventud en Málaga con las que caracterizarían su vida de exiliado en México, unos veinte años después. Hablando, ya al final de su vida, sobre el origen de sus actividades políticas, Prados habría de referirse al profundo sentimiento de culpa (y de angustia) que empezó a sufrir, al irse dando cuenta, desde muy joven, de los privilegios de que gozaba como hijo de una familia bien acomodada ${ }^{16}$. Y todo parece indicar que fue esta intuición primeriza lo que motivó la constancia en su línea de conducta; una conducta, como confirman estas dos prosas, siempre preocupada por buscar el bienestar de esa infancia desamparada que el poeta había contemplado desde la perspectiva privilegiada de su propia niñez.

James Valender

El Colegio de México

15 Véase Pla Brugat, op. cit., p. 115.

${ }^{16}$ En otra carta a Sanchis-Banús, fechada el 11-X-58. Apud HernándeZ, op. cit., t. 1, p. 425 . 
